\section{Facilitating Anastomosis Grouping of Rhizoctonia solani Isolates from Cool- season Turfgrasses}

\author{
Mei Zhang and Peter H. Dernoeden \\ Department of Agronomy, University of Maryland, College Park, MD 20742
}

Additional index words. bentgrass, brown patch, perennial ryegrass, tall fescue

\begin{abstract}
Determining anastomosis groups (AGs) of Rhizoctonia solani Kühn isolates is tedious and time-consuming. Three previously described methods (i.e., cellophane strip, glass slide, petri dish) were compared to determine which was the most rapid and accurate. Colony characteristics also were assessed to tentatively identify AGs. All techniques were accurate. The cellophane strip method was most time-consuming, and the time required for hyphal overlap with the glass slide method was not generally predictable. Pairing isolates in a petri dish containing a thin layer of water agar was reliable and was the simplest technique. There was little variation in colony pigmentation or sclerotia color, shape, or formation patterns within AG-1 IA $(n=34)$, AG-2-2 IIIB $(n=46)$, and AG-4 (n = 5); the former two AGs are the ones most commonly isolated from cool-season turfgrasses. Accordingly, $R$. solani isolates from turfgrasses may be assigned tentatively to an AG based on colony pigmentation and sclerotial characteristics.
\end{abstract}

Rhizoctonia solani incites brown patch, which affects numerous species of cool- and warm-season turfgrasses (Haygood and Martin, 1990; Smiley et al., 1992). Anastomosis is an important taxonomic tool, and isolates belonging to the same anastomosis group (AG) may be associated with a different or specific turfgrass species, geographic region, or level of pathogenicity (Sneh et al., 1991). Six $R$. solani AGs or subgroups have been identified from turfgrasses. They are AG-1, AG-2-2, AG-3, AG-4, AG-5, and AG-6 (Burpee and Martin, 1992; Champaco and Mihail, 1992; Green et al., 1993; Haygood and Martin, 1990; Hurd and Grisham, 1983; Martin, 1987; Martin and Lucas, 1984; Rowley, 1991; Yuen et al., 1994; Zarlengo et al., 1994). The most commonly isolated AGs from cool-season turfgrasses are AG-1 IA and AG-2-2 IIIB, followed by AG-4 (Burpee and Martin, 1992; Rowley, 1991).

Assigning isolates to AGs is based on imperfect hyphal fusion. Several techniques have been described, and all methods determine AGs by pairing unknown isolates with "tester" strains. Isolates may be paired on 1) water agar in petri dishes (Ogoshi et al., 1979; Parmeter et al., 1969; Rowley, 1991); 2) cellophane strips placed on an agar medium (Carling et al., 1987; Castro et al., 1983; Parmeter et al., 1969); or 3) a bare slide placed in a moist chamber (Kronland and Stanghellini, 1988).

\footnotetext{
Received for publication 6 Mar. 1995. Accepted for publication 24 May 1995. Scientific article no. A6626 and contribution no. 8843 of the Maryland Agricultural Experiment Station. The cost of publishing this paper was defrayed in part by the payment of page charges. Under postal regulations, this paper therefore must be hereby marked advertisement solely to indicate this fact.
}

Laboratory preparation and observation of hyphal fusion to determine $\mathrm{AG}$ are tedious and time-consuming processes. The three described techniques for $\mathrm{AG}$ determination have not been compared for their facility. Hence, the primary objective of this research involved comparing these three techniques for accuracy, ease of imperfect fusion observation and of preparation. Sherwood (1969) reported that AGs differ in cultural appearance, hyphal width, and growth rate. Working with $R$. solani isolates from cool-season turfgrasses, however, Rowley (1991) and Zhang (1994) found that hyphal width measurements and radial growth rate data were not reliable for use in determining AG. A secondary objective, therefore, was to evaluate colony characteristics to determine their usefulness in tentatively asment would reduce time by helping to eliminate superfluous pairings. This research focused on isolates of $R$. solani belonging to AGs most commonly associated with coolseason turfgrasses.

\section{Materials and Methods}

Sources of R. solani isolates. All R. solani isolates were collected from turfgrasses. Six out of 10 isolates (i.e., MD Rs-1, MD Rs-3, MD Rs-4, MD Rs-5, MD Rs-7, and MD Rs20) were obtained from lesions on perennial ryegrass (Lolium perenne L.) leaves. The other four $R$. solani isolates were obtained from leaf lesions on bentgrasses (Agrostis spp.) (i.e., MD Rs-8 and MD Rs-9) and tall fescue (Festuca arundinacea Schreb.) (i.e., MD Rs10 and MD Rs-23). The tester isolates evaluated were AG-1 IA, AG-2-1, AG-2-2 IIIB, AG-3, AG-4, AG-5, AG-6, and AG-7. These isolates were provided by L.L. Burpee (Univ. of Georgia, Georgia Station, Griffin), M.M. Kulik (U.S. Dept. of Agriculture-Agricultural Research Service, Beltsville, Md.), L.V. signing an isolate to an AG. Tentative place-
Rowley (formerly of the Univ. of Massachusetts, Amherst), and N.A. Tisserat (Kansas State Univ., Manhattan).

$A G$ determination methods. The methods evaluated were 1) petri dishes (PD) containing $2 \%$ water agar (WA); 2) rectangular cellophane strips (CS); and 3) clean glass slides (GS). For the PD method, a mycelial disk (7.0 $\mathrm{mm}$ in diameter) of a tester isolate was placed in the center of each petri dish $(100 \times 15 \mathrm{~mm})$. Three mycelial disks ( $7.0 \mathrm{~mm}$ in diameter) of the same unknown isolate then were placed 2 to $3 \mathrm{~cm}$ apart, surrounding the tester disk. During the initial evaluation, we determined that WA depth was important in the PD method. To improve observation, the amount of WA was reduced from 20 to $3 \mathrm{ml} /$ plate. In the CS method, the isolates were paired on $1 \times 8-\mathrm{cm}$ rectangular strips placed on $2 \%$ WA in petri dishes. Sterilized cellophane rectangles were dipped first in molten Difco potato dextrose agar (PDA) (13 g.liter ${ }^{-1}$ ), and two strips were then laid criss-cross on WA. A mycelial disk of a tester isolate was placed in the center, and one disk of the same unknown isolate was placed on each end of both strips, for a total of four. In the GS method, mycelial disks were placed on a glass slide, which was cleaned by dipping in $95 \%$ ethanol and wiping dry. A disk of an AG tester isolate was then placed 2 to 3 $\mathrm{cm}$ from a mycelial disk of the unknown isolate. Each slide was placed in a $100 \times 15$ $\mathrm{mm}$ petri dish lined with filter paper moistened with sterilized distilled water. In all methods, mycelium disks were obtained from the edge of an actively growing colony and were incubated at 22C until hyphae overlapped.

Staining and observation. To observe imperfect fusion, the area of hyphal overlap was stained with $0.05 \%$ trypan blue in lactophenol. In the PD method, the plate was rinsed with distilled water after staining. The plate was placed directly on the microscope stage to observe hyphal fusion. For the CS method, the strips were removed from agar, placed on a slide, stained, and then examined microscopically. In the GS method, the slide was removed from the petri dish, excess moisture was wiped from the bottom of the slide, then stained, and examined microscopically. Hyphal fusion was checked at $100 \times$ and confirmed at $450 \times$. Three subsamples of each tester isolate were paired with the 10 isolates in each method. The evaluation was performed twice, but due to difficulty in observing fusion with the PD method $(20 \mathrm{ml} /$ plate $)$ in the initial evaluation, only data from the second evaluation are shown.

Frequency of hyphal anastomosis was determined according to fusion type. The three types of fusion are perfect fusion, imperfect fusion, and contact fusion (Matsumoto, 1932). All anastomosing hyphae were traced back to their source to avoid any false positives or selffusion. Fusion frequency was calculated as a percentage by dividing the sum of fusion points by the total number of contact points in three subsamples with a total of 50 counts for each isolate (Kim and Yoshino, 1988). Contact points include fusion points plus all other points in the microscopic field where hyphae contact one another either by abutting or when 
crossing or paralleling one another. According to Kim and Yoshino (1988), fusion frequencies of $>50 \%, 30 \%$ to $49 \%$, or $<29 \%$ are considered as high, moderate, and low frequencies, respectively.

Colony characteristics. A mycelial disk (7 $\mathrm{mm}$ in diameter) of PDA was removed from the margin of an actively growing colony, and placed in the center of a petri dish $(100 \times 15$ $\mathrm{mm})$ containing PDA. Three plates of each isolate were randomly arranged in a dark incubator maintained at either $12 \pm 1 \mathrm{C}$ or $28 \pm 1 \mathrm{C}$. Colony characteristics, such as the color, size, and shape of sclerotia and colony pigmentation, were recorded and described after 25 days at $12 \mathrm{C}$ or after 15 days at $28 \mathrm{C}$. This experiment was repeated to ensure reproducibility of results.

\section{Results and Discussion}

$A G$ determination methods. The 10 initially unidentified isolates had moderate or high fusion frequencies with tester isolates AG-1 IA, AG-2-2 IIIB, or AG-4 using all three methods (Table 1). Tester isolates AGs 2-1, 3 , 5,6 , and 7 had fusion frequencies of $0 \%$ to $6 \%$ among isolates; therefore, data are not shown. Isolates designated MD Rs-1, MD Rs-4, MD Rs-5, and MD Rs-10 exhibited imperfect and contact fusions with the AG-1 IA tester. Although there were occasional areas of hyphal contact, these isolates did not anastomose with AG-2-1, AG-2-2 IIIB, AG-3, AG-4, AG-5, AG-6, or AG-7. Isolates designated MD Rs-7, MD Rs-8, MD Rs-9, and MD Rs-23 exhibited imperfect and contact anastomoses with AG2-2 IIIB, but did not fuse with AG-2-1, AG-3, AG-4, AG-6, or AG-7. Occasionally, however, they exhibited low fusion frequencies with AG-1 IA and AG-5. The MD Rs-3 and MD Rs-20 isolates anastomosed with AG-4 but failed to anastomose with AG-2-1, AG-3, or AG-6; there was an occasional hyphal contact with AG-1 IA, AG-2-2 IIIB, AG-5, and AG-7. Hence, MD Rs-1, MD Rs-4, MD Rs-5, and MD Rs-10 were assigned to AG-1 IA; MD Rs-7, MD Rs-8, MD Rs-9, and MD Rs-23 were assigned to AG-2-2 IIIB; and MD Rs-3 and MD Rs-20 were assigned to AG-4. There were small variations in fusion frequency percentages among techniques. Except for MD Rs-8 using the GS method, all methods provided moderate to high frequencies for each unknown isolate-tester isolate combination.

The PD method was the simplest. During initial evaluations, the WA was too thick $(\approx 7$ $\mathrm{mm}$ ) and hyphae grew at different depths; as a result, observation of anastomosis was difficult. This problem was overcome by reducing agar concentration (2.0\% to $1.6 \%)$ and pouring hot medium into dishes to achieve a very thin film of WA $(\approx 3 \mathrm{ml} /$ plate, $\approx 1 \mathrm{~mm}$ in depth $)$. The thin film essentially eliminated the problem of hyphae growing deeply into WA, which resulted in greatly improved anastomosis observation. A satisfactory hyphal overlap area could be obtained within $24 \mathrm{~h}$ at $22 \mathrm{C}$ with 2 - to 4-day-old colonies.

The CS method provided the best means of clearly observing hyphal fusion. The prepara-

Table 1. Comparison of Rhizoctonia solani anastomosis reactions of 10 unknown isolates with three AG tester isolates using petri dish (PD), cellophane strip (CS), and glass slide (GS) techniques.

\begin{tabular}{|c|c|c|c|c|c|c|c|c|c|}
\hline \multirow{3}{*}{$\begin{array}{l}\text { Isolate } \\
\text { MD Rs }\end{array}$} & \multicolumn{9}{|c|}{ Fusion frequency ${ }^{z}$} \\
\hline & \multicolumn{3}{|c|}{ AG-I IA } & \multicolumn{3}{|c|}{ AG-2-2 IIIB } & \multicolumn{3}{|c|}{ AG-4 } \\
\hline & PD & $\mathrm{CS}$ & $\overline{\mathrm{GS}}$ & $\overline{P D}$ & $\mathrm{CS}$ & $\overline{G S}$ & $\overline{P D}$ & $\mathrm{CS}$ & $\overline{G S}$ \\
\hline 1 & 30 & 44 & 39 & 2 & 0 & 0 & 0 & 0 & 0 \\
\hline 3 & 0 & 0 & 0 & 0 & 0 & 2 & 50 & 44 & 32 \\
\hline 4 & 52 & 37 & 48 & 2 & 0 & 0 & 0 & 0 & 0 \\
\hline 5 & 30 & 41 & 30 & 0 & 0 & 0 & 0 & 0 & 0 \\
\hline 7 & 1 & 2 & 0 & 60 & 50 & 37 & 0 & 0 & 0 \\
\hline 8 & 0 & 6 & 0 & 60 & 48 & 24 & 0 & 0 & 0 \\
\hline 9 & 2 & 3 & 0 & 60 & 54 & 50 & 0 & 0 & 0 \\
\hline 10 & 30 & 38 & 36 & 2 & 5 & 0 & 0 & 0 & 0 \\
\hline 20 & 0 & 0 & 2 & 0 & 0 & 0 & 53 & 32 & 33 \\
\hline 23 & 0 & 2 & 0 & 47 & 40 & 48 & 0 & 0 & 0 \\
\hline
\end{tabular}

${ }^{\mathrm{z}}$ Fusion frequency is a percentage determined by dividing the sum of fusion points by the sum of contact points in three subsamples with 50 counts.

tion involved in this technique, however, was more intricate and time-consuming when compared to either the PD or GS methods.

The limiting factor for the GS method was variability in the amount of time required for isolates to grow from the medium and across the slide. Generally, the amount of time for anastomosis to occur was not predictable, despite incubation at a constant temperature. Also, the mycelial disks would frequently slide across the glass due to moisture buildup in petri dishes, causing the hyphal overlap area to move.

Colony characteristics. Hyphal pigment and sclerotia size, shape, and number varied more among isolates grown at 12 than $28 \mathrm{C}$, possibly because at $12 \mathrm{C}$ most isolates took $>10$ days to completely cover the agar, whereas at $28 \mathrm{C}$, most isolates required only 2 or 3 days to completely cover agar and form sclerotia. At $28 \mathrm{C}$, the pattern of sclerotia formation, colony color, and other characteristics were relatively stable features of those AGs commonly associated with cool-season turfgrasses. Chand and Logan (1983) divided isolates of $R$. solani of AG-2-2 and AG-3 into six groups according to sclerotial patterns. Using terminology similar to that of Chand and Logan (1983), we divided our isolates into three culture groups. The colony characteristics described below are only for isolates of AG-1 IA (Group I), AG-2-2 (Group II), and AG-4 (Group III) grown at 28C. These groupings were assessed twice for reproducibility. A total of 34,46 , and 5 isolates were compared for Groups I, II, and III, respectively.

Group I. Only isolates of AG-1 IA are found in Group I. Characteristics of Types A and $\mathrm{B}$ are as follows: Type A: mycelium initially white then usually turning light brown; sometimes dark reddish-brown; young colonies (i.e., 2 to 3 days), mycelium sparsely to moderately aerial; sclerotia sometimes few in number, but usually produced in abundance; uniform in size, most $>1.5 \mathrm{~mm}$ in diameter; distributed over entire agar surface; spherical with a slightly flattened bottom; scattered singly or sometimes joined laterally; surface smooth, firm, finely fuzzy, and sometimes finely pitted where a brown exudate occurs; sclerotia very dark brown at maturity. Type B: mycelium color was a slightly darker brown than Type A after sclerotia were produced.
Sclerotia few to moderately abundant; variable in size from 1.0 to $10.0 \mathrm{~mm}$ in diameter, usually with a few large sclerotia $(>5 \mathrm{~mm}$ in diameter); sclerotia produced on the agar surface in the center or at the margin of petri dishes; sclerotia spheroid or subspheroid; often aggregated into compound sclerotia; brown droplets exude from sclerotia; sclerotia surface usually mycelioid, sometimes becoming hard and pitted; sclerotial surface initially white, becoming light to medium or reddishbrown.

Group II. Only isolates of AG-2-2 IIIB are found in this group. Mycelium initially light to dark camel-brown or reddish-brown; older colonies are very dark brown; mycelium appressed to moderately aerial; uniform texture and color over the colony; concentric zonation in most isolates. Sclerotia few to abundant; usually small ( 0.5 to $1.0 \mathrm{~mm}$ in diameter), and rounded, and usually on agar surface; surface wooly, loose; surface color similar to or darker than mycelial color.

Group III. Only isolates of AG-4 are found in this group. Mycelium initially white, turning moderate to dark brown, usually with a powdery-gray surface; mycelium appressed, but occasionally aerial; usually with conspicuous brown hyphae radiating from the disk. Sclerotia are few or many; usually small $(<1.0$ $\mathrm{mm}$ in diameter) and embedded in the agar; sclerotia flat or rounded, and dark brown to black.

In summary, the PD method was the most rapid technique for determining AG. Rhizoctonia solani sclerotia patterns, color, shape and size, colony pigments, and other mycelial traits were similar among isolates from within AG-1 IA, AG-2-2 IIIB, and AG-4 when grown at $28 \mathrm{C}$. The most prominent characteristics are summarized in Table 2, and they appear to be stable and, therefore, useful in tentatively identifying AGs of $R$. solani isolates from coolseason turfgrasses. Additional evaluation of more isolates from various geographic regions should be conducted to confirm the validity of these groupings. Hyphal fusion, therefore, remains the only reliable method for assigning $R$. solani isolates to AGs. Selection of the most appropriate brown patch management strategy, such as cultivar or fungicide selection, eventually may be linked to knowing the AG of the pathogen. 
Table 2. Distinguishing colony characteristics of Rhizoctonia solani isolates representing AG-1 IA, AG-22 IIIB, and AG-4 from cool-season turfgrasses.

\begin{tabular}{|c|c|c|}
\hline $\begin{array}{l}\text { Culture } \\
\text { group }\end{array}$ & $\begin{array}{l}\text { AG } \\
\text { group }\end{array}$ & Distinguishing colony characteristics ${ }^{2}$ \\
\hline \multirow[t]{3}{*}{$\bar{I}$} & AG-1 IA & \\
\hline & Type A & $\begin{array}{l}\text { Colonies brown or light brown and slightly } \\
\text { wooly; sclerotia mostly } 2 \text { to } 5 \text { mm in diam- } \\
\text { eter; distributed uniformly over agar } \\
\text { surface; spherical with slightly flattened } \\
\text { bottom. }\end{array}$ \\
\hline & Type B & $\begin{array}{l}\text { Mycelium darker brown when compared } \\
\text { to Type A. Sclerotia produced on agar } \\
\text { surface in the center or at the margin of } \\
\text { dishes; often aggregated into compound } \\
\text { sclerotia, normally a few sclerotia }>5 \\
\text { mm in diameter. }\end{array}$ \\
\hline II & AG2-2 IIIB & $\begin{array}{l}\text { Colonies dark brown; concentric color } \\
\text { zones; sclerotia small, } 1 \text { to } 2 \mathrm{~mm} \text {, and } \\
\text { sclerotial color darker brown than the } \\
\text { mycelium. }\end{array}$ \\
\hline III & AG-4 & $\begin{array}{l}\text { Colonies with a powdery-gray surface; } \\
\text { usually a few sclerotia on the surface of } \\
\text { agar; hyphae compact and appressed } \\
\text { on surface; underside of colony dark } \\
\text { brown;but generally no concentric zones. }\end{array}$ \\
\hline
\end{tabular}

${ }^{2}$ Colony characteristics for isolates grown at $28 \mathrm{C}$ on potato dextrose agar and after sclerotia were produced.

\section{Literature Cited}

Burpee, L.L. and B. Martin. 1992. Biology of Rhizoctonia species associated with turfgrasses. Plant Dis. 76:112-117.

Carling, D.E., R.H. Leiner, and K.M. Kebler. 1987. Characterization of a new anastomosis group (AG-9) of Rhizoctonia solani. Phytopathology 77:1609-1612.

Castro, C., J.R. Davis, and M.V. Wiese. 1983. Differential medium for identification of Rhizoctonia solani AG-3. Plant Dis. 67:1069-1071.

Champaco, E.R. and J.D. Mihail. 1992. Spatial and temporal patterns of anastomosis groups of Rhizoctonia solani from disease patches of naturally infected tall fescue. Phytopathology 82:1079. (Abstr.)

Chand, T. and C. Logan. 1983. Cultural and pathogenic variation in potato isolates of Rhizoctonia solani in Northern Ireland.
Trans. Brit. Mycol. Soc. 81:585-589.

Green, D.E., II, J.D. Fry, J.C. Pair, and N.A. Tisserat 1993. Pathogenicity of Rhizoctonia solani AG2-2 and Ophiosphaerella herpotricha on zoysiagrass. Plant Dis. 77:1040-1044.

Haygood, R.A. and S.B. Martin. 1990. Characterization and pathogenicity of species of Rhizoctonia associated with centipedegrass and St. Augustinegrass in South Carolina. Plant Dis. 74:510-514.

Hurd, B. and M.P. Grisham. 1983. Rhizoctonia spp. associated with brown patch of Saint Augustinegrass. Phytopathology 73:1661-1665.

Kim, W.G. and R. Yoshino. 1988. Characteristics in hyphal anastomosis of Rhizoctonia solani AGI (IA) in relation to locality and cultural ages of the isolates. Ann. Phytopathol. Soc. Jpn. 54:141150.

Kronland, W.C. and M.E. Stanghellini. 1988. Clean slide technique for the observation of anastomo- sis and nuclear condition of Rhizoctonia solani. Phytopathology 78:820-822.

Martin, B. 1987. Rapid tentative identification of Rhizoctonia spp. associated with diseased turfgrasses. Plant Dis. 71:47-49.

Martin, S.B. and L.T. Lucas. 1984. Characterization and pathogenicity of Rhizoctonia spp. and binucleate Rhizoctonia-like fungi from turfgrasses in North Carolina. Phytopathology 74:170-175.

Matsumoto, T. 1932. Physiology and parasitology of the fungi generally referred to as Hypochnus sasaki Shirai. I. Differentiation of the strains by means of hyphal fusion and culture in differential media. J. Soc. Trop. Agr. 4:370-388.

Ogoshi, A., M. Oniki, R. Sakai, and T. Ui. 1979. Anastomosis grouping among isolates of binucleate Rhizoctonia. Trans. Mycol. Soc. Jpn. 20:33-39.

Parmeter, J.R., Jr., R.T. Sherwood, and W.D. Platt. 1969. Anastomosis grouping among isolates of Thanatephorus cucumeris. Phytopathology 59:1270-1278.

Rowley, L.V. 1991. Applied epidemiology of Rhizoctonia spp. on turfgrass. MS Thesis, Dept. of Plant Pathology, Univ. of Massachusetts, Amherst.

Sherwood, R.T. 1969. Morphology and physiology in four anastomosis groups of Thanatephorus cucumeris. Phytopathology 59:1924-1929.

Smiley, R.W., P.H. Dernoeden, and B.B. Clarke. 1992. Compendium of turfgrass diseases. 2nd ed. APS Press, St. Paul, Minn.

Sneh, B., L. Burpee, and A. Ogoshi. 1991. Identification of Rhizoctonia species. APS Press, St. Paul, Minn.

Yuen, G.Y., M.L. Craig, and L.J. Giesler. 1994. Biological control of Rhizoctonia solani on tall fescue using fungal antagonists. Plant Dis. 78:118-123

Zarlengo, P.J., C.S. Rothrock, and J.W. King. 1994. Influence of shading on the response of tall fescue cultivars to Rhizoctonia solani AG-1 IA. Plant Dis. 78:126-129.

Zhang, M. 1994. Rhizoctonia solani Kühn anastomosis groups and fungi associated with turfgrasses affected by brown patch. MS Thesis, Dept. of Agronomy, Univ. of Maryland, College Park. 